\title{
LA INTIMIDAD EXTERIORIZADA. UN BIEN JURÍDICO A PROTEGER
}

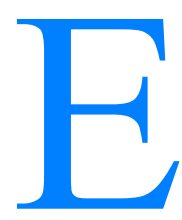

n este artículo, sin perder de vista las raíces históricas, y desde una perspectiva crítica capaz de contemplar el contraste entre las exigencias que demanda en la actualidad el derecho a la intimidad y la normativa constitucional y su posterior desarrollo legislativo, reconsideraremos cuál es el bien jurídico que se trata de preservar y las particularidades provenientes de la titularidad. Entre las razones apremiantes para esta revisión juega un papel estelar la actual reivindicación doctrinal de un supuesto derecho a la autodeterminación informativa. Cuando desde un sector de la doctrina se insiste en la premura de reconocer la categoría autónoma de un derecho, ubicado entre los llamados de tercera generación, hay que empezar a pensar que, o bien las informaciones que nos atañen han cobrado tal magnitud que requieren su reconsideración como objeto de protección de un nuevo derecho -lo que supondría señalar la barrera que lo distancia del derecho a la intimidad sin por ello dejarlo sin contenido propio, a la vez que tratar de ahondar en las raíces justificatorias del nuevo derecho-, o bien reconocer que se trata de una exigencia implícita en un derecho fundamental consolidado entre los llamados de primera generación, el derecho a la intimidad, en cuyo caso, urge enfrentarse a las causas que han impulsado la salida de la parte básica del contenido de ese derecho en busca de otro amparo constitucional. Habría que averiguar si razones de tipo conceptual o acaso de ausencia de operatividad han motivado el que las informaciones busquen refugio en una trinchera más fuerte, o de mayor impacto reivindicativo. Asumir esta perspectiva del problema implica, en nuestra opinión, entre otras muchas cosas, aceptar, como se ha señalado, que la dicotomía público-privado es una realidad sometida a un proceso de revisión, admitir la afloración de nuevos ámbitos que se resisten a la tradicional catalogación, y por supuesto reconocer como un fenómeno presente en nuestros días a «...la intensificación 
de lo íntimo como esfera de valoración propia...» con todas las consecuencias que estas consideraciones conllevan, entre las que se sitúan la necesidad de establecer la distinción entre tres ámbitos bien diferenciados, lo público, lo privado y lo íntimo; el desplazamiento de la tradicional dicotomía y la concentración en la esfera de la intimidad de numerosas situaciones conflictuales ${ }^{1}$. En cualquier caso, resulta apremiante un replanteamiento de qué es el derecho a la intimidad ${ }^{2}$, y esta precisión conceptual exige, en nuestra opinión, como paso previo, la reconsideración de cuál es el bien jurídico que trata de proteger, asunto del que intentaremos fundamentalmente ocuparnos en estas líneas.

Tomaremos como marco básico de referencia del presente estudio, la configuración española actual del derecho a la intimidad; es decir, su cualificación como derecho fundamental en la Constitución española de 1978, su incardinación con las restantes categorías de derechos de la persona y su viabilidad dentro del marco internacional, especialmente el europeo, hacia el que debe tendencialmente desarrollarse toda tentativa de interpretación de la normativa jurídico-positiva de alcance interno.

El esfuerzo de aproximación conceptual no es posible, en nuestra opinión y como ya hemos apuntado, sin la estipulación previa de cuál es el bien jurídico protegido, elemento con frecuencia eludido pero absolutamente determinante en esta discusión. A nuestro modo de ver, la intimidad, aunque no sin matizaciones, es la necesidad básica ${ }^{3}$

${ }^{1}$ Cfr. en J. J. Aguirre de la Hoz, «La pareja dicotómica público-privado: ¿disolución de la dicotomía?» Comunicación presentada en la VII Semana de Ética y Filosofía Política, Valencia 14-16 de diciembre de 1992.

2 Conviene advertir ya desde aquí que el propósito que guía estas líneas está predominantemente dirigido por el objetivo de maximización de un criterio de utilidad en cuanto técnica operativa que facilite la labor de los diversos operadores jurídicos y, por tanto, no atiende ni a la elaboración de una distinción real entre lo privado y lo íntimo, de muy difícil consecución pues, en nuestra opinión, no podría prescindir de la casuística, ni desde luego pretende realizar una conceptualización de corte esencialista del mundo íntimo. Al contrario, este punto de partida significa asumir la diferencia existente entre una distinción artificial pero operativa y otra artificiosa y abogar, desde luego, por la primera.

${ }^{3}$ Damos por supuesta la conexión entre la teoría de las necesidades y los derechos humanos en orden a su fundamentación sin que de ello se infiera la, a nuestro juicio, errónea reducción entre derechos humanos y necesidades básicas. Sobre el concepto de necesidades básicas y su utilidad en el discurso justificatorio sobre derechos humanos puede verse entre otros, A. E. Pérez Luño, Derechos humanos, Estado de Derecho y Constitución, Tecnos, Madrid, 1984, págs. 162 y ss., así como las diversas aportaciones publicadas bajo el rótulo «Sobre necesidades básicas» en el número 7 de la Revista Doxa, Alicante, 1990 (especialmente, J. De Lucas y M. J. Añón, «Necesidades, razones y derechos») y más recientemente, M. J. Añón, «Fundamentación de los derechos humanos y necesidades básicas» en Derechos Humanos, A.A V.V., Tecnos, Madrid, 1991, págs. 100 y ss. Ed. J. Ballesteros. 
que está en la base de las exigencias de este derecho; su distinción del «ámbito privado»va a proporcionar argumento suficiente para dotar de carácter autónomo al derecho a la intimidad dentro de un genérico derecho a la vida privada; para ello puede ser útil un breve examen histórico de las raíces configurativas de su cualificación de derecho fundamental, es decir, de las distintas fases por las que ha atravesado su plasmación positiva porque ayudará a determinar el tipo de exigencias que desde su aparición lo sustentan. Junto a la determinación del bien jurídico objeto de protección, otro elemento estructural que puede contribuir en la elucidación conceptual y que en nuestra opinión, requiere la máxima atención, consiste en la identificación del titular del derecho. Se trataría de esclarecer (en la actual configuración de los derechos fundamentales) a qué sujetos se atribuye la titularidad y el ejercicio del derecho, esto es, la identificación del titular y el estudio de las diversas situaciones en que se disocia la titularidad del ejercicio.

En segundo lugar, y ante la extrañeza que pueda ocasionar el trato preferente y aislado que desde aquí se propone del bien jurídico que trata de proteger el derecho a la intimidad personal, frente al tratamiento constitucional del derecho a la intimidad personal y familiar y, por lo tanto, a la ausencia de un tratamiento conjunto del derecho a la intimidad personal y familiar, conviene explicitar las causas que han motivado esta premeditada omisión ${ }^{4}$.

\section{I}

Como es evidente, la primera precisión apuntada no puede quedar reducida a dos líneas pues, a las dificultades generales de cualquier definición jurídica, se suman los obstáculos específicos con que tropieza este intento ante un derecho -el de la intimidad- que refiere a un concepto ambiguo e impreciso y al que se recurre con tanta facilidad como se huye de su elaboración conceptual. En efecto, tanto la intimidad como el derecho al que ella ha dado lugar, son conceptos rodeados de una fuerte carga emotiva, relativos, graduales, contingentes y variables, lo que dificulta enormemente cualquier aproximación conceptual ${ }^{5}$. Además, paradójicamente, el mayor grado de utilidad y efectividad de este derecho se alcanza a

${ }^{4}$ Sobre todo si se tiene en cuenta que una lectura literal del art. 18.1 de la C.E. induce a una interpretación bien distinta. Textualmente dice: «Se garantiza el derecho al honor, a la intimidad personal y familiar y a la propia imagen».

${ }^{5}$ Un breve repaso doctrinal da muestra del alcance de esta afirmación sobre las dificultades de precisión conceptual. Creemos que Pérez Luño acierta al señalar a la amplitud y dispersión de su objeto como la posible causa de la ausencia de una unívoca y precisa definición legal o jurisprudencial, cfr. A. E. PérezLuño, Derechos humanos, Estado de Derecho y Constitución, op. cit., pág. 327. Sin embargo, la ambigüedad 
través de su configuración abierta a las nuevas manifestaciones posibles. Esta idea remite, en la fase de su juridificación, a esa efectividad potencial de los derechos fundamentales capaz de ofrecer una protección que abarque a las futuras exigencias que se produzcan dentro de su ámbito de aplicación (como, por ejemplo, las injerencias en la intimidad en la variedad de situaciones que plantean los cambios de sexo o los, cada vez más frecuentes supuestos de S.I.D.A., las nuevas investigaciones sobre el genoma humano, o las manipulaciones que pueden acompañar a los futuros bancos de datos), sin que por tal se entienda el abandono de su contenido esencial ${ }^{6}$ al regateo político, o, aún peor, al ideológico. Esta pretensión de textura abierta de la norma encuentra su equilibrio en que, al mismo tiempo, debe satisfacer el requisito de la precisión de unos contornos capaces de distanciarle de otro tipo de derechos y figuras afines.

Hemos partido del carácter relativo del derecho a la intimidad; quizá sería más correcto hablar de la relatividad de la idea que se tiene de ese tan reclamado, en ocasiones, concepto normativo. La referencia viene marcada por la graduación existente dentro de los elementos a barajar en la delimitación de este derecho. La diversidad de sus titulares, la amplitud de manifestaciones que comprende su contenido, así como la exigencia expresa de contemplar las circunstancias que rodean cada caso concreto en función de los factores

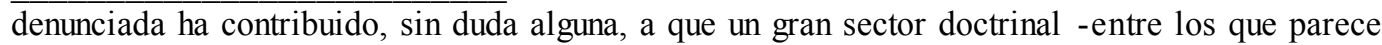
situarse el propio prof. Pérez Luño-, en base a la aparición y posterior evolución de estas exigencias de intimidad, llegan a la identificación como figuras análogas de la Privacy y la noción de intimidad en nuestra propia tradición jurídica, cfr. A. E. Pérez Luño, en Derechos humanos, Estado de Derecho y Constitución, op. cit., pág. 324, e incluso, creemos que es determinante de su posición posterior de abogar por una categoría general o forma única de garantía jurídica sobre el problema de si es un único derecho general a la intimidad o varios derechos de la personalidad imposibles de constituir una única categoría. A esta identificación no es ajeno García San Miguel que tras señalar la distancia entre la clásica definición de Warren y Brandeis de privacy y las exigencias actuales de este derecho termina por definir al derecho a la intimidad en términos de derecho a no ser conocidos en ciertos aspectos por los demás, un derecho al secreto y por calificarlo de un derecho discutido y discutible, cfr. L. García San Miguel, «Reflexiones sobre la intimidad como límite de la libertad de expresión» en Estudios sobre el derecho a la intimidad, AAVV, Ed. L. García San Miguel, Tecnos, Madrid, 1992, págs. 15 y ss. En nuestra opinión, existe en efecto una identidad de ratio en la protección de unos intereses que pueden comprenderse bajo un derecho general a la privacidad en el que el derecho a la intimidad no es más que una manifestación específica, la más importante, como intentaremos demostrar. De ahí que nos parezca relevante su tratamiento aislado.

${ }^{6}$ Sobre el problema del contenido esencial de los derechos fundamentales vid. su consideración de valor absoluto, de «límite de los límites» en L. PRIETO SANCHÍS, Estudios sobre derechos fundamentales, Debate, Madrid, 1990, págs. 139 y ss. Vid. también las sentencias STC. 11/1981 de 8 de abril y STC 77/1982 de 20 de diciembre. 
sociales, culturales y económicos (por ejemplo, entre el contexto urbano y el rural o, entre el subsistema social y el cultural) y, en definitiva, las pautas de comportamiento deducidas en función de las reglas sociales de su entorno y la aceptación de las mismas por los sujetos en cuestión, son datos que no se pueden olvidar en la configuración general de este derecho ni, menos aún, en su aplicación específica; como relativo ha sido también, sin duda alguna, en su trayectoria histórica. Además, no se descarta que el desarrollo creacional-jurisprudencial de los derechos fundamentales favorezca esta contingencia.

Lo hasta aquí señalado tiene mucha más importancia de lo que a primera vista pueda parecer ya que la posición que se adopte ante el problema conceptual nos parece que es una condición resolutiva de una cuestión a la que todavía no se le ha dado una solución unitaria, el carácter autónomo o no de este derecho. Una concepción amplia, incapaz de establecer los límites entre la esfera privada y la intimidad, permitiría la entrada a supuestos de figuras afines como las del honor, o la imagen o, incluso, el secreto de las comunicaciones, la inviolabilidad del domicilio, etc.; por el contrario, una concepción restringida debería aportar los suficientes requisitos como para aislar el derecho a la intimidad de toda manifestación circundante y a la vez terminar con una preocupación constante en la doctrina, más acuciante entre los civilistas, si se trata de un derecho de la personalidad o del reconocimiento de varios.

En el intento de dar luz a todas estas cuestiones constituye una aportación nada desechable la realización de un breve recorrido por el proceso de positivación del derecho a la intimidad, así como por su variable trayectoria teórico-doctrinal. Se trata de llegar al apuntalamiento de algunas notas sobre las nociones de intimidad y vida privada, guiados, más que por un ánimo de exhaustividad, por la intención de ofrecer una visión integral que comprenda al panorama jurídico positivo como paso complementario en todo esfuerzo de aproximación conceptual a estos derechos.

Aunque históricamente se ha localizado ${ }^{7}$ al primer sujeto activo de este derecho en el hombre burgués del s. XIX, y doctrinalmente el «fuero interno» de Thomasio y Kant proporciona la raíz teórica, un breve repaso por la historia del constitucionalismo pone de manifiesto que no sólo es escasa su presencia en los textos fundamentales sino que, además, su configuración clara y expresa no se

${ }^{7}$ Ver en este sentido, la clara exposición de la aparición histórica y doctrinal del derecho a la intimidad que realiza Pérez Luño, en A. E. Pérez Luño, Derechos humanos, Estado de Derecho y Constitución, op. cit., concretamente en las págs. 321 y ss. 
produce hasta bien entrado el siglo XX. La constitución Mexicana de 1917, de forma genérica, recoge una protección especial al ámbito privado en su art. 16. La Constitución del II Reich Alemán de 1919 se limita a un reconocimiento global de la inviolabilidad de la libertad personal y a una posterior protección más detallada de determinadas libertades, entre las que no se menciona expresamente al derecho a la intimidad personal ni familiar. No será, por tanto, hasta la Constitución Portuguesa de 1976 cuando veamos de forma clara y expresa la proclamación del derecho a la intimidad personal y familiar, concretamente en su art. 26 y dentro de un rótulo general de reconocimiento de otros derechos personales. Posteriormente, la Constitución Española de 1978 se hará eco en su articulado de esta exigencia de forma expresa.

A nivel de declaraciones de derechos de índole internacional, aunque el reconocimiento expreso es anterior, no pasa de situarse a mediados del siglo XX, a la vez que predomina su configuración negativa, es decir, se trata de proteger contra las violaciones efectuadas a la intimidad y, en modo alguno se observan una intervención positiva por parte del Estado, sólo se actúa a posteriori. En esta línea, la Declaración Americana de 1948 recoge en su art. 5 el derecho a la protección legal contra los ataques a la vida privada y familiar; la Declaración Universal de los Derechos Humanos de 1948 también se hace eco de esta exigencia en su art. 12 y, en el mismo sentido, esto es, sólo en los supuestos ataques o injerencias actúa la protección. El Convenio Europeo para la Protección de los Derechos Humanos de 1950 recoge en su art. 8, al derecho al respeto de la vida privada y familiar de las personas. El pacto de derechos civiles de 1966 en su art. 17.1 defiende contra ingerencias arbitrarias o ilegales en la vida privada o familiar. Y, finalmente, la Convención Americana sobre Derechos Humanos de 1970, en su art. 11, protege este ámbito dentro de una protección genérica a la honra y a la dignidad, en el mismo sentido de impedir injerencias arbitrarias o abusivas.

Pero, ¿qué es la intimidad, el ámbito íntimo, la vida privada, la esfera privada, o la tan reclamada privacidad? ${ }^{8}$ Frecuentemente se recurre a la vía de la negociación para delimitar el ámbito de lo privado.

${ }^{8}$ Aquí utilizaremos como sinónimos vida privada y privacidad (término que, aunque poco afortunado se encuentra perfectamente acuñado a nivel doctrinal) a efectos puramente técnicos. No entraremos en la distinción de contenidos entre el término de origen anglosajón «Privacy» y nuestra noción de «vida privada» -por la imposibilidad fáctica de entender todas las cuestiones colaterales, no por ello menos importantes, que conlleva cualquier estudio-, centrando nuestra atención en las diferencias entre las nociones de intimidad y vida privada en el uso común y jurídico de nuestro entorno cultural más próximo. 
Así, se dirá que pertenece a esa esfera lo que no es público. El criterio por tanto determinante en la mayoría de los autores es el de la correspondencia y, a la vez, radical diferencia con su antónimo9. Afirmación, ésta, que, aunque no resuelve mucho en este momento histórico en que la frontera entre ambos se difumina y cada vez son mayores las zonas de penumbra, sin embargo, y a efectos de la distinción que aquí interesa señalar, proporciona una satisfactoria primera aproximación.

Nuestra propuesta se puede resumir en las siguientes ideas: en la dialéctica que se produce entre intimidad y privacidad, la intimidad acota las fronteras interiores del «ser persona» y la vida privada, sus fronteras exteriores. En este sentido, y, aunque la vida privada supone por una parte un paso previo a la intimidad, por otra la comprende sin llegar a corresponderse totalmente con ella, encontrando a su vez su límite en el ámbito público. De tal manera que se puede violar la vida privada y no violar la intimidad ${ }^{10}$, por ejemplo cuando se viola el domicilio ajeno, o se vulnera el secreto de las comunicaciones ${ }^{11}$. Sin embargo, cualquier violación de la intimidad supone una invasión de la vida privada, en cuanto que ésta actúa

${ }^{9}$ Bien sea para poner el acento en la esfera que lo público ha robado a lo privado o a la inversa, en función de la posición de partida. Cfr., entre otros, A. E. Pérez Luño, Derechos humanos, Estado de Derecho y Constitución, op. cit, yH. Béjar, El ámbito intimo. Privacidad, individualismo y modernidad. Alianza, Madrid, 1990 (1. ${ }^{\text {a }}$ edición de 1988). Asimismo confrontar la reciente caracterización de la dicotomía público-privado realizada por Aguirre de la Hoz y que toma como punto de partida la reciprocidad tanto real como conceptual de los términos. Vid. J. J. Aguirre de la Hoz, «La pareja dicotómica público-privado...» ya cit.

${ }^{10}$ Esta afirmación nos parece muy importante porque impide la identificación, lamentablemente frecuente, entre estas dos nociones y aporta una razón para intentar su delimitación conceptual, aunque, a nuestro modo de ver, por supuesto, no excluye las zonas de penumbra y en este sentido, cobra importancia la tesis de Carrió sobre los derechos periféricos en los casos de penumbra constitucional, en cuanto plus de garantía de los derechos específicos y a la vez freno eficaz de la expansión arbitraria del catálogo de derechos fundamentales y de la trampa que, en ocasiones, encierra la titularidad colectiva en materia de derechos fundamentales al poder abocar en unos supuestos derechos fundamentales de la sociedad y, en última instancia, ¿por qué no?, en la policía de pensamiento de Orwell, cfr. A. D. Carrió, «Derecho constitucional a la privacidad: Zonas claras de protección y zonas de penumbra» en La autonomía personal, C.E.C., Madrid, 1992, págs. 109 y ss.

${ }^{11}$ En nuestra opinión, y ante la reciente influencia de casos en que se observa este tipo de intromisiones, lo más que se puede argumentar, si se demuestra, es que se produce una invasión de la esfera privada por la violación del secreto de las comunicaciones pero -coherentemente con nuestra propuesta de una noción estricta de intimidad- parece poco afortunado el recurso a la intimidad en las situaciones, como éstas, en que la presencia de la nota de alteridad desvanece todo asomo de posibilidad de recurrir al amparo del derecho a la intimidad. Se trata por tanto, insistimos, en su caso, de invasiones a la privacidad en una de sus manifestaciones posibles, el derecho al secreto de las comunicaciones. 
como una fase previa pero, a la vez, totalizadora de la esfera espiritual y material de la persona en que se concreta la intimidad. Decimos material, porque, al contrario que algunas posiciones $^{12}$, consideramos que una de las mayores peculiaridades de la noción de intimidad proviene de su sentido dual. Esto quiere decir que estamos ante una noción en la que pueden observarse claramente dos significados; el primero de ellos se queda en la fase de pensamientos, creencias, sensaciones y sentimientos sin signos perceptibles para ser identificados externamente. Evidentemente, este contenido no puede ser objeto de protección por el Derecho porque, y ésta es una particularidad del Derecho, éste no puede proteger lo que no reconoce, lo intangible, lo inmaterial. Por tanto, su contenido sólo interesa al Derecho cuando su conocimiento es posible a través de su exteriorización material, aunque su origen último sea totalmente espiritual, sin que ello signifique salir de la esfera de lo íntimo ${ }^{13}$. Es, en definitiva, una de tantas nociones ambivalentes que tiene a su favor la posibilidad de delimitar las coordenadas dentro

${ }^{12}$ Es frecuente entre la doctrina civilista, a partir de F. De Castro, la omisión de este aspecto material y el reduccionismo que observa sólo el aspecto espiritual de la intimidad. La propuesta de este autor de sustituir la idea de los derechos de la personalidad por la de bienes de la personalidad al objeto de superar la dificultad de catalogación en el marco de los derechos subjetivos implica la consideración de estos bienes como no materiales. Esto produce, en nuestra opinión, una consecuencia inmediata, el bien jurídico protegido es, en todo caso, inmaterial e intangible; lo que a su vez ocasiona grandes problemas, pues ¿cómo puede regular y proteger el Derecho algo etéreo que no conoce más que de una forma intuitiva? Cfr. F. De Castro, «Los llamados derechos de la personalidad», A.D.C. 1959 y del mismo autor, Temas de Derecho Civil, Madrid, 1972.

${ }^{13}$ El que el interés jurídico por la intimidad provenga actualmente de su dimensión social no implica ignorar la doble faz de esta noción. Al contrario, supone una indagación más precisa de su significado que conduce a discernir el aspecto del mismo que le interesa al Derecho, la exteriorización de los comportamientos, y al mismo tiempo a rechazar en materia de derechos fundamentales toda mención a la interioridad de los comportamientos. Es una cuestión de ámbito de aplicación en la que, aunque compartimos, como ha tenido la amabilidad de señalarnos el profesor Pérez Luño, que «...lo que importa no es la mayor interioridad o exterioridad de un comportamiento, porque para tener relevancia jurídica siempre tendrá que exteriorizarse y tener una determinada dimensión social», no parece que esté de más, siempre y cuando no suponga un obstáculo que impida reconocer como también nos ha indicado Pérez Luño, la importancia «...en el ejercicio actual de la intimidad como derecho de los valores e intereses públicos y/o privados, que pueden contraponerse a los deseos de una persona concernida de mantener sus datos personales en un plano de reserva o desea ejercitar determinados controles sobre su difusión». Sin embargo discrepamos en que estas afirmaciones desplacen de modo absoluto el tradicional sistema de tutela de la intimidad basado en la intensidad social de la conducta consecuencia de la teoría de las esferas de la jurisprudencia alemana. Al contrario y, por nuestra parte, una reconsideración de la teoría de las esferas se traduce en una revisión y puesta al día de su capacidad de explicación de toda esta problemática y, 
de las cuales tiene lugar el contenido de intimidad objeto de protección del Derecho.

Pues bien, conforme a esta demarcación que hemos intentado realizar, el derecho a la intimidad del art. 18.1 de 1978 tiene como objeto de protección a la «intimidad» en su significado estricto señalado, mientras que el derecho al honor, al nombre, a la imagen, a la inviolabilidad del domicilio, o al secreto de las comunicaciones serían múltiples y específicas manifestaciones de la privacidad, cuyo bien jurídico protegido sería «el ámbito privado». De tal forma que habrá que estar al caso concreto para determinar cuándo por ejemplo la violación de un escrito va más allá de la mera invasión del ámbito privado para entrar de lleno en la llamada «intimidad» y para esta determinación actúa como un criterio decisivo el consentimiento o permisividad de su autor, lo que se podría traducir en su renuncia o no a esa parcela de intimidad.

En este sentido, y siguiendo con una línea de argumentación ejemplificativa, la lectura de un diario personal, ajena a la voluntad de su autor, supone una clara intromisión en su intimidad; sin embargo, la lectura consentida del mismo por un individuo ajeno, al implicar una renuncia implícita a esa parcela de intimidad, se traduce en la transformación del objeto jurídico protegido con el subsiguiente cese de protección por el derecho a la intimidad, pasando a formar parte del objeto de regulación de la llamada privacidad. Asistimos pues, al nacimiento de una relación jurídica entre dos individuos totalmente ubicada en la esfera privada en la que, además de aparecer un nuevo sujeto, el receptor, el objeto de protección, por la transformación acaecida, es distinto, identificándose con una parcela del ámbito privado. En esta relación, resulta indiferente, sin embargo, que el conocimiento de este primer receptor sea directo o indirecto, esto es, lectura personal o comunicación del propio autor por la vía que sea, pues lo determinante es la renuncia a esa parcela de intimidad por parte de autor. Sólo en un supuesto resulta jurídicamente relevante la forma utilizada, y es el caso de que se precise demostrar la veracidad del contenido de la información para ver si ha habido una supuesta posterior invasión de la privacidad. Si la comunicación del contenido proviene del propio autor, precisamente porque existe prueba tangible de corroboración -el diario personal- creemos que el Derecho sólo puede intervenir si existe concordancia entre la información emitida y la exteriorizada a través del diario pues, si la información transmitida no se ajustase al escrito de procedencia, por tratarse de una desfiguración

desde luego, en una selección de los aspectos recuperables de la misma. La posición de Pérez Luño puede verse claramente expresada en A. E. Pérez Luño, Libertad informática y leyes de protección de datos personales, en colab. con M. Losano y M. F. Guerrero Mateus, Centro de Estudios Constitucionales, Madrid, 1989, págs. 157 y ss. 
consciente de la realidad no podría probarse que lo que se transmite forma parte del contenido de la infimidad que significa el diario, por lo que, difícilmente se podría alegar que existe una renuncia a una parcela de la intimidad ni tampoco la consecuente invasión de la relación de privacidad al no existir parcela de intimidad exteriorizada anterior a la que renunciar. La adecuación de la intimidad renunciada y la intimidad exteriorizada es en estos supuestos imprescindible para la actuación judicial. Pero esto no quiere decir que en toda relación de privacidad sea valiosa, jurídicamente hablando, la veracidad del contenido de privacidad violado, sino sólo en los supuestos cuyo origen inmediato pueda ser localizado en una renuncia a la intimidad. Por un principio de coherencia, cualquier cadena de relaciones que se originase a posteriori se guiaría por el mismo criterio por estar montada sobre una farsa. De lo dicho se deriva la afirmación de que la veracidad de la información es relevante, no tanto por su autenticidad, y esto nos parece importante de destacar, como por su ajuste a las pruebas de identificación válidas para el Derecho.

Surge aquí un interrogante, ¿quiere esto decir que, en el caso de que a través de una comunicación directa a un tercero se transmitan datos falsos sobre una supuesta intimidad se está, conforme a nuestra propuesta, saliendo de la esfera de la intimidad y entrando en la de la esfera privada, a efectos de posteriores intromisiones? Esta pregunta estará en función a la respuesta que demos a otra anterior y condicionante, ¿entraría dentro del ámbito de regulación y protección del derecho a la intimidad las informaciones falsas exteriorizadas pero no comunicadas? esto es, ¿son relevantes para el Derecho la veracidad de las informaciones per se?, ¿puede el Derecho entrar en ese tipo de análisis? Creemos que no, pues el Derecho no puede entrar en su ámbito interior y sólo en el caso de una comunicación en desajuste con una prueba material es posible juzgar la adecuación de lo dicho con lo actuado y por lo tanto desplegar los mecanismos de protección en caso de violación.

No obstante, podemos ir más allá de esta nueva relación y observar otra supuesto distinto en el caso de que un tercero ajeno a esa primera relación lea o conozca del contenido de ese diario. Surge aquí otra relación jurídica en la que, sin duda alguna, se produce una violación ya que no existe el consentimiento del autor para dicha intromisión. En dicha relación es posible distinguir a su vez dos situaciones por la forma en que se ha realizado la violación. La forma aquí nos parece un criterio relevante para determinar el tipo de invasión por dos razones; la primera es que uno de los requisitos necesarios para identificar un ataque a la intimidad en cuanto objeto de protección por el Derecho, es la intromisión por vía material, y, la segunda, la consideración de que el conocimiento directo implica una toma de decisión individual y consciente por la que se asume 
plenamente la responsabilidad del acto. De lo que se deduce que la violación será de la intimidad o de la privacidad según exista o no conocimiento directo o indirecto del diario personal, esto es, por comunicación del contenido o por su lectura directa. El consentimiento individualizado del primer supuesto lo que transforma es la primera relación, pero no afecta a las nuevas posibles relaciones, ante las cuales, el contenido del diario sigue constituyendo un muro infranqueable. Estas afirmaciones parecen partir de la consideración del diario como un coto vedado de intimidad para el resto de los individuos. Cuestión ésta sobre la que volveremos más tarde.

La transmisión del contenido del diario personal a un tercero, sin el beneplácito del autor, por la persona que lo conoció y con el consentimiento del mismo, origina unos efectos distintos según las relaciones que se contemplen:

1. Entre los dos primeros sujetos -el autor y el primer receptor al que se le autorizóantes de la violación que produce la relación del primer receptor y el segundo, existe una relación de privacidad y en modo alguno invasión; situación ésta que como veremos se transformará.

2. La relación entre el segundo receptor y el primero puede ser o no de privacidad (admitimos que el conocimiento del diario personal puede hacerse a un individuo con el que se comparte la vida privada o a terceros con los que no une esfera privada alguna, ejemplo una revista de gran difusión) pero, en todo caso, origina una violación de la esfera privada del autor en la medida en que un contenido de la misma ha salido sin autorización y la responsabilidad debería extenderse tanto al emisor como al tercero difusor. Lo que sería imposible es alargar la extensión de la violación del derecho a cuartos receptores, por ejemplo lectores de la revista, en todo caso sería un criterio cualificador del daño producido a efectos de la responsabilidad civil del segundo y tercer receptor.

3. Entre el segundo receptor y el autor, al no existir relación de privacidad, se produce una violación de la privacidad del autor de forma indirecta o, de su intimidad por la vía indirecta, pues el segundo receptor no estaba autorizado a recibir esa información.

4. Finalmente, en la relación de privacidad entre el $1 .^{\circ}$ receptor y el autor -por cuanto en ese contenido se habían sobrepasado los límites de lo íntimo y entrado de lleno en la esfera de lo privado por renuncia del autor- tras las violaciones señaladas, se origina una invasión de la privacidad. A esta relación, ya establecida, no le afectan 
las otras relaciones que se han ido formando mas que en cuanto una invasión añadida de la privacidad, tanto sea por comunicación directa o indirecta.

Lo hasta aquí dicho se podría esquemáticamente transcribir de la siguiente manera:

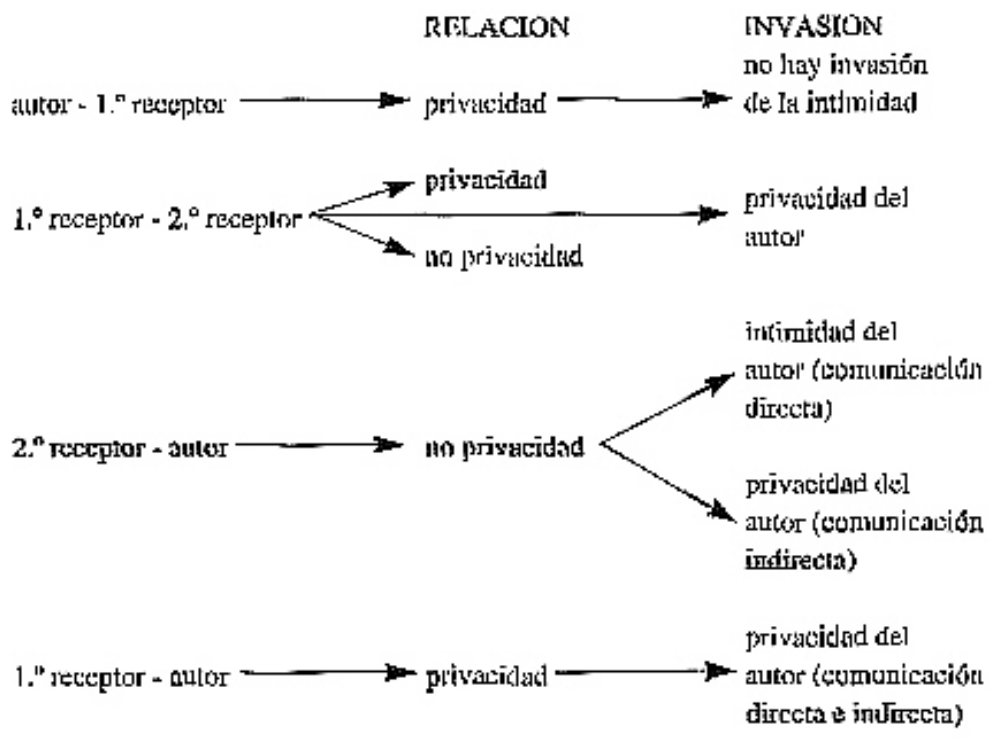

Pero, entonces, y, a la vista de este esquema, ¿qué supuestos reservamos a la intromisión de la intimidad? En principio, todas las violaciones por parte de terceros de la esfera no comunicada pero sí exteriorizada de nuestra interioridad. Indiscutiblemente parece necesario añadir un tercer criterio para la identificación de este objeto so pena de dejarlo reducido a una noción tan estricta que resulte inoperante. La determinación del contenido parece, a la vista de lo expuesto y retornando una idea anteriormente apuntada, el tercer elemento decisivo en la delimitación de esta noción jurídica al jugar, a nuestro modo de ver, un papel importante, no sólo para ver en qué supuestos se habla de intimidad, en cuanto objeto de protección por el Derecho sino, también, para dar entrada a todas las informaciones personales que exteriorizadas materialmente forman parte del muro infranqueable para terceros. Estamos por ejemplo pensando en las informaciones médicas. Se podría perfectamente sostener que los datos sobre la salud de un individuo son en sí íntimos, no para el médico que dispone de ellos -porque aquí hay comunicación a una segunda persona con consentimiento de su titular pues la mera visita 
a un médico implica la renuncia tácita a esa esfera de la intimidad y la aparición sobre el contenido de losa datos de una relación de privacidad doctor/paciente-, sino para cualquier tercero posible receptor sin nuestro consentimiento de esa información. Este ejemplo podría extenderse a las relaciones entre cualquier tipo de sujetos (sea la administración o una sociedad privada, por ejemplo una compañía de seguros y un particular, sea entre particulares, pues lo relevante no es que el receptor sea una persona física o jurídica sino el consentimiento expreso de la fuente última originaria de datos) y pretende dar entrada dentro de la denominada intimidad exteriorizada a los bancos de datos sobre su persona. Lo que sí parece claro de la actual regulación legal es que el derecho a la intimidad es de los sujetos individualmente considerados; otro asunto distinto es el ejercicio de la protección civil para el cual expresamente se contempla en la ley la posibilidad de que el sujeto demandante de la reparación de la intromisión sea una persona jurídica ${ }^{14}$; como asunto distinto es también la identificación del sujeto demandado, para el que no parece haber obstáculo alguno pensar en una persona jurídica.

Llegado a este punto parece recomendable hacer una síntesis de lo expuesto:

1. Nuestra propuesta sugiere que la intimidad se identifica con el fuero interno y que su contenido estaría formado por pensamientos, creencias, emociones y sensaciones, esto es, informaciones totalmente propias al ser humano que, como él, y en base a su individualidad, participan de la nota de singularidad. Pero, y aquí viene la segunda gran peculiaridad, al Derecho sólo le interesa la exteriorización de estas informaciones en la que juega un papel decisivo el elemento racional al permitir la elección de planes de vida y pautas de comportamiento como consecuencia de la autonomía moral. El elemento irracional aún existiendo y formando parte de la noción de protección al Derecho. Es por tanto «la intimidad exteriorizada» el bien jurídico protegido por el derecho a la intimidad del art. 18.1 de la C.E., aunque, insistimos, no sea éste el único contenido de la noción de intimidad.

2. Pero además, hay dos elementos que permiten una aproximación exacta. El primero de ellos es su no comunicación a terceros; en este sentido, frases tan utilizadas como la de «intimidad compartida»

${ }^{14} \mathrm{El}$ art. 4.1 alude en el caso de ejercicio de acciones de protección civil del honor de una persona fallecida a la posibilidad de que por designación testamentaria recayese en personas jurídicas cfr. STC 19'/1983 y STC 137/1985. 
se situarían entre los errores terminológico-conceptuales frecuentes del lenguaje corriente. Desde nuestra propuesta, la intimidad no se puede compartir pues, en la medida en que se comparte alguna parcela del ámbito de aplicación de la noción de intimidad, se renuncia a ese aspecto de la intimidad y se origina una relación de privacidad. En todo caso se puede afirmar que se comparte la vida privada.

3. El segundo elemento, decisivo en la práctica jurídica, es la delimitación del contenido de las informaciones ${ }^{15}$ que, bajo parámetros

${ }^{15} \mathrm{Al}$ efecto de apreciar más perceptiblemente el requisito de la relevancia del contenido puede resultar interesante su estudio mediante una situaciones hipotéticas reflejadas para mayor claridad a través de unos sencillos ejemplos. Si establecemos que:

(A) = Andrés; (B) = Luis; C = médico que ha efectuado el cambio de sexo de (A); (D) = médico analista que ha realizado los análisis de $(\mathrm{B}) ;(\mathrm{E})=$ sujeto, conocido por los médicos $(\mathrm{C})$ y (D) $\mathrm{y}$, a la vez paciente de $(\mathrm{B}) ;(\mathrm{x})=$ un posible contenido de la esfera íntima de $(\mathrm{A})=$ datos médicos sobre un reciente cambio de sexo; $\left(\mathrm{x}^{\prime}\right)=$ un posible contenido de la esfera íntima de $(\mathrm{B})=$ datos médicos sobre su reciente condición de seropositivo; $(\mathrm{O})=$ el Ordenamiento jurídico; $(\mathrm{e})=$ comunicación del contenido $(\mathrm{x})$ señalado por parte de $(\mathrm{C})$ a $(\mathrm{E})$ en un bar; $\left(\mathrm{e}^{\prime}\right)$ = comunicación del contenido $\left(\mathrm{x}^{\prime}\right)$ señalado por parte de (D) a (E) en un bar; $(\mathrm{a}, \mathrm{b}, \mathrm{c})=$ circunstancias personales, sociales, económicas y culturales. A saber, individuo de 26 años, antes Laura, persona privada sin proyección pública, ambiente rural pequeño, funcionario de la administración pública nivel E, ingresos económicos medios, cultura media, recientemente sometida a un cambio de sexo; $(\mathrm{d}, \mathrm{e}, \mathrm{f})=$ circunstancias personales, sociales, económicas y culturales. A saber, individuo de 36 años, persona privada sin proyección pública, ambiente urbano, soltero. Estomatólogo con consulta privada, ingresos económicos altos, amplia cultura. $(\mathrm{F}, \mathrm{G}, \mathrm{H})=$ el resto de personas, las del entorno más próximo de (A) en cuanto asimilable; $(\mathrm{I}, \mathrm{J}, \mathrm{K})=$ el resto de personas, las del entorno más próximo de $(\mathrm{B})$ en cuanto asimilable. En este sentido el contenido (x) de la esfera íntima de (A) será íntimo jurídicamente hablando para $(\mathrm{O})$ y por tanto frente a (E) si y solo si, ante la comunicación de (e) de (C) y, a la vista de las circunstancias $(a, b, c)$ constituye relevante su consideración como tal a juicio de $(\mathrm{A})$ y del resto de $(F, G, H)$. Pero esta afirmación no supone que el contenido (x') de (B) que él considera dentro de su esfera íntima sea relevante jurídicamente en cuanto objeto de protección del derecho a la intimidad para $(\mathrm{O})$ y frente a $(\mathrm{E})$ por la comunicación (e') de (D) si las circunstancias que se dan son (d,e,f), En este caso, no basta que (B) considera a ( $\left.x^{\prime}\right)$ parte de su esfera íntima; para que (O) proteja las intromisiones de $\left(x^{\prime}\right)$, debe producirse el binomio de aceptabilidad entre $(B)$ y $(I, J, K)$ en base al reconocimiento de la relevancia para $(\mathrm{B})$ de (x') junto al análisis de las circunstancias (d,e,f). En este sentido el tercer requisito que proponemos, el contenido relevante, no sólo sirve para delimitar el exacto alcance del ámbito de aplicación de este derecho, sino que es fundamental para la coexistencia con los restantes derechos fundamentales al indicar en qué casos prevalecerá una exigencia individual frente a un interés colectivo. Por supuesto habría que entrar también, según el esquema anterior, en la diversidad de relaciones que se producen y en las formas de conocimiento. Queremos con este ejemplo indicar que a la hora de juzgar la relevancia de una exigencia concreta, no basta, aunque sea necesaria, la importancia subjetiva e incluso objetiva de la misma sino que, a ese requisito hay que añadir de la objetivación 
de flexibilidad, se concretará en función de su relevancia tanto para el sujeto en cuestión como para su entorno social. Estos datos, imprescindibles para acotar el tipo de informaciones sujetas a protección, exigen un análisis contextualizado de los casos concretos que contemple fundamentalmente las condiciones que rodean el actuar cotidiano social e individual.

Llegados a este punto surge una cuestión apremiante, ¿qué razones juegan a favor de una protección más específica a la intimidad que la genérica de la que goza la privacidad? Se trataría de explicitar qué clase de argumentos sostienen la cualificación jurídica específica de un bien, la intimidad exteriorizada, cuando, podría argumentarse una defensa igualmente eficaz a través de su inclusión dentro de la genérica privacidad. Esta respuesta supone la entrada en el discurso justificatorio sobre el derecho fundamental a la intimidad y el abandono momentáneo del presente debate conceptual, aunque también parece factible alegar razones de índole pragmático.

No creemos que haya grandes problemas en afirmar que la clave de bóveda radica en la importancia de lo que se trata de preservar, la esfera más interior de la persona jurídicamente protegible. Los componentes citados, en cuanto son la esencia de la misma, deberían gozar, si no de la máxima protección -pues ha de combinarse con la protección de otro tipo de valores constitucionalmente amparados- sí de un sistema de garantías más específico que se traduzca por un lado, en normas que a la par que posibiliten su respeto favorezcan el desarrollo individualizado de la personalidad y, por otro, en el reconocimiento del poder de control sobre informaciones que nos atañen; y esto no tiene por qué desvirtuarse ante su indiscutible remisión a la vía interpretativa, en caso de conflicto con las libertades constitucionalmente protegidas.

Pudiera objetarse el escaso número de intromisiones constatadas, pero no obstante, consideramos que centrar exclusivamente la atención en la cantidad de violaciones supone no contemplar la cuestión en toda su extensión, esto es, olvidarse de los elementos cualitativos

de la pretensión deducida de las circunstancias que rodean el caso concreto imprescindible para que el mecanismo jurídico de protección se ponga en marcha. A esta objetivación de la pretensión puede serle aplicable la línea de argumentación que desarrollan Añón y De Lucas -salvando la distancia entre necesidades básicas y exigencias- del apartado sobre el carácter objetivable de las necesidades en su propuesta de fundamentación de los derechos humanos desde las necesidades básicas en M.J. Añón y J. De Lucas en «Necesidades, Razones y Derechos», ya cit. Por otra parte, la elección de este tipo de ejemplo parte de la línea argumentativa que sostiene Rivero de distinguir entre intimidad y vida privada, lo que a su vez permite una ulterior distinción del secreto y la confidencialidad apoyada por la STS de 20 de febrero de 1989, cfr., en A.A.V.V., Parte general de Derecho Civil, Vol. II. Personas, Ed. La Cruz Bosch, Barcelona, 1990. 
y, por tanto, no parece un criterio decisivo en materia de derechos fundamentales, sobre todo si tenemos en cuenta que, el hecho de que no se llegue en muchas ocasiones a los tribunales, no conlleva la infravaloración de los asuntos. Al contrario, otros órdenes de motivaciones son las causantes del difícil acceso a la justicia.

Pero, entonces, ¿cuáles son en definitiva los elementos que delimitan las fronteras entre la intimidad exteriorizada y el ámbito privado a efectos de la protección específica del derecho a la intimidad o de cualquiera de las manifestaciones concretas de la privacidad constituidas como derechos fundamentales? En el ámbito privado no íntimo, el elemento racional adquiere absoluta presencia. Nuestra esfera privada es la que queremos como tal configurar. La protección jurídica permite ejercer ese control personal, ya que en virtud del elemento volitivo marcaremos los límites internos de la misma, constituyendo la prueba más fehaciente de nuestra autonomía moral (los límites externos vienen marcados por la necesaria delimitación de las esferas pública y privada). Pero esto no es suficiente para su distinción, surge aquí la necesidad de contemplar otro elemento capaz de establecer las coordenadas delimitadoras y, ¿qué mejor candidato que su comunicación o participación a terceros?

De aquí que podamos afirmar que la intimidad, en cuanto objeto de protección del derecho a la intimidad, es un bien jurídico cuanto menos problemático. Sobre todo si se tiene en cuenta que, la intimidad, en las ocasiones en que no se pasa a la fase de exteriorización material es intangible, inaprehensible e imprevisible y, al mismo tiempo, tan esencial al individuo que su ausencia implica su muerte, su inexistencia. No se concibe pues la propia existencia del ser humano sin esta parcela y, sin embargo, el Derecho no puede extender sus redes más allá de la intimidad exteriorizable, pues, insistimos, ¿cómo proteger lo que no se conoce? En este sentido, el Derecho aún no ha entrado en el mundo de la infraconsciencia, en cuanto fase anterior a la formación de pensamientos, creencias, sensaciones y emociones. Tampoco puede descartarse que algún día los avances tecnológicos permitan la entrada en la mente humana y, con ello, en ésa, en estos momentos, utópica protección.

En cuanto a la propuesta conceptual expuesta, se nos ocurren algunas otras objeciones como, por ejemplo, la adecuación de la misma a los seres carentes de razón. Al respecto, creemos que no habría grandes dificultades en reconocerlos titulares de derechos pero, la exigencia de los componentes citados tornaría su ejercicio verdaderamente problemático. Este tema sólo parece poder resolverse, a pesar de lo paradójico que resulta con nuestra propuesta sobre el contenido del derecho a la intimidad, mediante la conjugación de dos criterios, los mecanismos de sustitución de la capacidad de obrar 
que contempla el Derecho en concordancia con los conocimientos que proporcionan los avances del mundo científico. En este sentido, hasta donde la ciencia médica ha llegado, parece que mientras hay actividad cerebral y fisiológica, hay vida, y consecuentemente el bien jurídico a proteger, la intimidad exteriorizada, está presente ${ }^{16}$; lo paradójico es que, de acuerdo a la actual regulación legal, aún en casos de muerte cerebral, no habría inconveniente en reconocer cierta garantía de un derecho a la intimidad desde el momento en que el legislador y la Jurisprudencia establecen una ficción en orden a su protección civil pues la memoria de un sujeto de derecho fallecido, constituye una prolongación de su personalidad y como tal es tutelada por el Derecho ${ }^{17}$. Más problemático resulta responder a los supuestos en que hay actividad cerebral pero es difícil que se produzca la conexión con la exteriorización de la misma -personas vegetativas, en las que hay actividad cerebral pero no exteriorización- quizá, y en la línea de excepción a la regla general que es la ficción legal del supuesto de fallecimiento, la memoria, en este caso -de su pasado-, sería una prolongación de su personalidad y como tal objeto de protección por el derecho ${ }^{18}$.

En definitiva, la línea de argumentación desarrollada aporta razones a favor de la admisión de dos fases en la noción de intimidad, de las cuales sólo una es objeto de protección jurídica y reconduce el problema de su delimitación con la privacidad a la observación en cada caso concreto de la presencia de los elementos citados. En los supuestos de atentado a la intimidad, la no comunicación, la exteriorización material y la relevancia del contenido serán los criterios relevantes. Quedaría reservada la observancia de la presencia de dos elementos, el volitivo y la alteridad, para la delimitación de los supuestos de invasión de la esfera privada. Por supuesto, en la privacidad se manejan otro tipo de elementos que la distancian de la esfera

${ }^{16}$ Esta afirmación, llevada a sus últimas consecuencias, significa, entre otras cosas, que el diario de un demente o de un afectado por el Síndrome de Down, por seguir el ejemplo del texto, supondría en todo caso una manifestación de su intimidad exteriorizada. Cuestiones bien distintas serían la de quien puede ejercer el derecho frente a una posible violación y la de si otro tipo de intereses -materializados por ejemplo, en el acceso médico a esos papeles para corroborar los resultados de determinados tratamientos- podrían primar, en caso de conflicto y, por tanto, en qué circunstancias prevalecerían para su calificación de no intromisión.

${ }^{17}$ Cfr. la Exposición de Motivos de la L. O. de 5 de mayo de 1982 sobre la protección civil del derecho al honor, a la intimidad personal y familiar y a la propia imagen y los art. 4, 5 y 6 de la citada ley.

${ }^{18}$ Argumento que podría también venir avalado por la propia exposición de motivos cuando se señala que «...la muerte del sujeto de derecho extingue los derechos de la personalidad...». Está claro que en estos supuestos al haber actividad cerebral, hay científicamente vida y, desde luego, personalidad civil conforme a los arts. 29 y 32 del C. C. 
pública, en los que ahora no entraremos, pero sólo los dos citados bastan, en nuestra opinión, para su delimitación de la intimidad. Ello no debe hacernos olvidar que la intimidad supone una parcela de la privacidad, seguramente la más interior, y que se refiere a ese conjunto de componentes aprehensibles a través de su exteriorización.

En cuanto al segundo elemento de análisis estructural señalado y, a pesar de que la determinación de la titularidad de un derecho parece una cuestión obvia, a nuestro modo de ver, en el derecho a la intimidad requiere una especial atención, por la diversidad, que, por razón de la titularidad, se produce en el alcance del ejercicio de este tipo de derecho. Concretamente, en el derecho a la intimidad, y, a modo de apuntes sobre esta cuestión, pueden distinguirse claramente entre la persona privada y la persona privada de proyección pública, distinción apoyada por el diferente tratamiento jurisprudencial, doctrinal, no así constitucional, y por el amplio margen que el legislador deja en manos del juez ${ }^{19}$. Sin embargo, existen precedentes jurisprudenciales que van más allá de esta distinción genérica por los que podrían hacerse depender del estado civil de las personas diversas consecuencias jurídicas en cuanto al alcance de este derecho ${ }^{20}$. Sin embargo,

${ }^{19}$ La L. O. de 5 de mayo de 1982 no hace mención alguna a esta distinción en los supuestos que contempla ataques a la intimidad, no así en los de protección de la imagen. Sin embargo la doctrina suele dedicar un apartado a la repercusión de la distinción entre persona privada o pública en función de la variabilidad del objeto de protección, la intimidad. Así se afirma por O'callagham que en el caso de personas de actividad pública, la intimidad recognoscible disminuye, se difumina, en beneficio de los ciudadanos. Desde esta premisa se llega a que los ciudadanos tienen derecho (el subrayado es nuestro) a conocer datos verdaderos de su círculo íntimo. Sinceramente, esta última afirmación nos parece excesiva sobre todo si consideramos que en su apoyo se citan una serie de sentencias concretamente, S.T.C. $171 / 1990$ de 12 de noviembre, S.T.C. $172 / 1190$ de 12 de noviembre, S.T.S. de 7 de septiembre de 1990 en las que, en nuestra opinión, una interpretación adecuada no pasa de señalar que el simple acceso a un cargo público o el ejercicio de una actividad pública implica una renuncia implícita a determinados aspectos de la intimidad por lo que, conforme a la propuesta que desde aquí se realiza, esos contenidos quedan plenamente dentro de la esfera privada, lo que no evita su posible colisión con un interés público, pero sin que de ello se derive un supuesto derecho popular a informaciones privadas de personajes públicos. Cfr. el estudio que lleva a cabo X. O'callaghan, Libertad de expresión y sus límites: honor, intimidad e imagen, Rev. de Derecho Privado, Derechos Reunidos, Madrid, 1991, págs. 90 y ss., cfr. también las STS de 18 de junio de 1988 o la STS de 28 de octubre de 1986 y la del STC 231/1988.

${ }^{20}$ En este sentido se ha pronunciado una reciente sentencia de la Audiencia Provincial de Madrid al hacer hincapié en la distinción entre el ámbito de intimidad de una persona y la cesión bilateral de una parte de esa intimidad como cuota que pasa a integrarse en la vida privada de la pareja. La renuncia implícita a ciertos aspectos de la intimidad en la situación de convivencia marital permite, a nuestro juicio, realizar una distinción en la titularidad por razón del estado civil, siempre que no se interprete como una disminución en la titularidad, cfr. S. 19/92 de la Audiencia Provincial de Madrid. 
consideramos que ambos supuestos se refieren a las posibilidades de ejercicio del derecho, esto quiere decir que lo que se altera es el objeto del derecho, la intimidad, por renuncia a ciertos aspectos de la misma, pero no la titularidad, ya que la reducción del objeto no significa el despojo de la titularidad, a pesar de que la distinción se realice en función de la diversidad de titulares. También se puede atender a una distinción entre persona viva o no en orden a su protección civil. En el supuesto de persona fallecida como ya hemos señalado con anterioridad, se produce la ficción legal por la cual la memoria de la misma actúa como impulsora de la titularidad de tal forma que se aprecian diferentes situaciones según la violación se hubiese producido antes o después del fallecimiento.

Parece por tanto una premisa generalmente aceptada que la determinación del bien jurídico objeto de protección propio de cada derecho fundamental es una cuestión no exenta de dificultades en determinados derechos. Pues bien, en nuestra opinión, si el derecho a la intimidad tiene un carácter diferenciador con respecto a otro tipo de derechos de tratamiento tradicionalmente conjunto, es precisamente aquí donde hay que detenerse, en la determinación y caracteres esenciales del bien jurídico objeto de protección, es decir, en las peculiaridades que acompañan a la intimidad, peculiaridad que se acentúa por cuanto se podría sostener que el reconocimiento de este derecho, tan íntimamente ligado a la individualidad humana en su configuración y requerimiento y en su propia particularidad, no tendría sentido si el hombre no viviese en sociedad. Se podría objetar que, desde ese punto de vista, ningún derecho tendría sentido. De acuerdo, pero esta segunda observación que tratamos de señalar y que supone un aumento de su carácter peculiar no se detiene en esa observación genérica y va más allá, a un nuevo dato mucho más concreto, el de que el reconocimiento del grado de intimidad a proteger de la persona -determinado por el número de manifestaciones posibles de la misma- está en función de su inserción en un contexto social determinado ${ }^{21}$. Indiscutiblemente no son comparables las circunstancias en que se desarrollan las exigencias de intimidad de un individuo en un contexto rural pequeño, que en un desorbitante contexto urbano, lo que puede incluso hacer variable el tipo de exigencias. Por seguir con uno de los ejemplos anteriores, en una aldea de escaso número de habitantes es difícil que se produzcan intromisiones en la intimidad de las personas por la vía informática.

${ }^{21}$ Esta idea se encuentra implícitamente recogida, aunque con una formulación poco clara en el art. 2.1 de la L. O. de 5 de mayo de 1982 al aludir «....al ámbito que, por sus propios actos, mantenga cada persona reservado...». 


\section{II}

La omisión señalada líneas arriba, obedece, en primer lugar, a que el concepto estricto de intimidad ${ }^{22}$ que se está proponiendo parte del cuestionamiento del rótulo que protege la esfera familiar. Se trata de una discrepancia de técnica legislativa por considerar que la esfera privada que, en ocasiones, conlleva la vida familiar queda al margen del ámbito íntimo. Una vez más el enunciado de un derecho ocasiona confusión pues, desde nuestra propuesta, no sólo no corresponde a la relación que se produce en dicha esfera familiar el calificativo de íntimo sino que además, y aún pudiendo referirse en muchas ocasiones a la vida privada, no siempre la mal llamada intimidad familiar se identifica con privacidad. La familia de origen, viene dada, no la elegimos y el hecho de que se produzcan en su contexto situaciones comprensibles dentro de la privacidad, contexto que como mucho estaríamos dispuestos a admitir que favorece en principio la aparición de este tipo de relaciones, no significa que nuestra total esfera privada quede prisionera dentro del entorno familiar. En este sentido, y si no son términos equiparables, más difícil resulta aún admitir desde el concepto estricto de intimidad que aquí se sostiene que se pueda hablar de intimidad familiar, en cuanto objeto de protección por el Derecho, porque la alteridad presente en ella es propia, según hemos visto, de la vida privada y en modo alguno de la noción jurídica de intimidad. Se observa sin embargo en numerosas ocasiones la presencia del elemento racional o volitivo -cuando como en cualquier otro contexto de privacidad se elige al depositario o receptor de la esfera privada- pero vivir bajo el mismo techo, insistimos, no supone vida privada sino, en todo caso y como ya hemos señalado, la delimitación de un contorno más favorable a su realización. De todos es conocido la existencia de familias entre cuyos miembros no existe el menor átomo de privacidad porque lo único que comparten es un habitáculo común, requisito éste que no parece suficiente aunque si aparezca regularmente en la noción de privacidad. La privacidad, y este dato es absolutamente relevante, supone compartir un espacio común, espacio que no es sólo ni siempre físico. Lo que conlleva las notas de alteridad y voluntariedad. De estas consideraciones cabría extraer la existencia de tres esferas diferenciadas, la esfera íntima, la esfera privada, y la esfera familiar que conforme a la tesis

${ }^{22}$ Parece conveniente detenerse en la idea de que la propuesta del texto de un concepto estricto de intimidad no debe interpretarse como una conceptuación estática. Sin embargo, el situarse en la línea doctrinal favorable al carácter dinámico de los derechos fundamentales no creemos que invalide o que convierta en innecesarios los intentos de aproximación conceptual con fines prioritariamente operativos. 
formulada deberían responder a los siguientes enunciados: No todo lo privado es íntimo, lo íntimo pasa la barrera hacia lo genuinamente privado al hacer su presencia la nota de la alteridad, lo familiar no es nunca íntimo (lo íntimo no puede ser nunca familiar). Puede ser privado o no serlo. Finalmente, lo privado no tiene por qué ser siempre familiar. Esto plantea el problema de los incapaces de decidir, a los cuales no puede negarse el reconocimiento de un derecho a la privacidad, pero en los que el elemento volitivo tendrá que solucionarse, una vez más, a través de los mecanismos de sustitución que el derecho contempla, por ejemplo tutores.

A la vista de lo hasta aquí expuesto parece factible esbozar ya algunas conclusiones derivadas de las precisiones conceptuales que hemos tratado de señalar:

1. En todo propósito de aproximación conceptual de un derecho fundamental constituye, en nuestra opinión, un paso previo la estipulación de cuál es el bien jurídico protegido. En el derecho que nos ocupa y, entre los posibles candidatos, parece que la «intimidad exteriorizada» reúne las exigencias que subyacen al reconocimiento de este derecho. Sin embargo, esta aseveración no impide reconocer la particularidad de este objeto de protección que, tratándose de un bien inmaterial e intangible, sólo se identifica en un segundo nivel mediante su actuación material, lo que permite hablar de la noción de intimidad en términos de ambivalencia o de doble manifestación, espiritual y material.

2. En segundo lugar, ante la multitud de problemas y objeciones con que ha tenido que enfrentarse la elucidación conceptual del derecho a la intimidad, y como consecuencia del punto anterior, nuestra propuesta se concreta en la sustitución de la preocupación centrada en la obtención de un concepto claro y preciso del derecho a la intimidad -dada la relatividad que le acompaña- por la maximización de una idea: el establecimiento de sus parámetros identificatorios, estos es, los mínimos y máximos entre los que es posible situar la diversidad de situaciones jurídicas que se contemplan bajo ese rótulo. El camino que nos parece más adecuado es el de la observancia de los requisitos necesarios para la actuación del derecho. Además esta postura contaría con el apoyo constitucional (que no entra en definiciones) y su proyección legal en la L. O. del 82 (que se inclina por establecer en su articulado las notas que lo caracterizan, así como el ámbito de protección a través de una lista abierta de posibles intromisiones).

3. En tercer lugar, la actual configuración constitucional del derecho a la intimidad (art. 18.1 de la C. E.) exige, de una vez por 
todas y, con carácter urgente, partir de una primaria observación: su consideración de derecho fundamental, lo cual, inevitablemente, y en nuestra opinión, traslada a un segundo plano, como mínimo, el problema de si es, o no, uno o varios derechos de la personalidad. En este nivel de juridificación lo decisivo es deducir a la luz de la normativa constitucional y teniendo en cuenta la ubicación del derecho, su formulación, el sistema de protección que lo ampara, sin olvidar su desarrollo legislativo posterior ni la aportación de los jueces en la creación del mismo, su significado y alcance actual, para que por sí sola se desvele cualquier cuestión colateral. Pero esta tarea, evidentemente, proporcionaría material para el desarrollo de un trabajo mucho más amplio del que se pretendía en estas líneas.

4. En cuarto lugar, el nivel de aproximación conceptual conseguido -por la vía de la delimitación del bien jurídico que se trata de preservar- permitirá la elucidación de un paso complementario y, a nuestro modo de ver, posterior, esto es, el establecimiento de sus notas definitorias, que servirá para comprobar la ausencia de la nota de inalienabilidad como banco de pruebas a favor del criterio predominante de ponderación de bienes.

5. Faltaría por considerar las consecuencias que estas precisiones conceptuales tienen sobre el llamado derecho de autodeterminación informativa también llamado de libertad informática. Pues bien, en nuestra opinión, resulta, al menos, cuestionado el recurso a un nuevo derecho fundamental -con todas las dificultades de reconocimiento, implantación y aceptación que conlleva la tercera generación de derechos- cuando una reformulación de un derecho fundamental, ya consagrado y asentado, recoge de forma clara las exigencias que podrían dar origen al nuevo derecho, las informaciones íntimas, su control, acceso y disposición. Sin embargo, podría objetarse que informaciones de otra índole, importantes para la persona pero no íntimas, quedarían fuera de este derecho. Ante este dato, no parece haber obstáculos en que se actúen a través del derecho público subjetivo contemplado en el art. 105. b, quedando el art. 18.1 reservado a la proyección subjetiva del derecho a la intimidad en cuanto derecho fundamental el 18.4 como su faceta objetiva, esto es, su garantía institucional ${ }^{23}$ a través del mandato legislativo. Ésta nos parece una interpretación conforme a la propuesta planteada, además de constituir un intento de ajuste de la normativa constitucional

${ }^{23}$ Cfr. STC 26/1987 de 27 de febrero. 
y la realidad social, respetuosa con el peso de la historia y, capaz de recoger las nuevas exigencias que la sociedad informatizada depare ${ }^{24}$.

${ }^{24}$ Lo que no debe interpretarse como un rechazo a la llamada tercera generación de derechos humanos, sino como una llamada a la prudencia ante la avalancha que en ese rótulo subyace sin que ello suponga ignorar la presencia de nuevas necesidades que se van canalizando en exigencias y que podrán dar lugar a nuevos derechos fundamentales. Esta postura, a su vez, no implica desconocimiento sobre el peligro que encierra uno de los puntos fuertes caracterizadores de dicha generación de derechos, las nuevas formas de titularidad que podrían desembocar a no tan largo plazo en una reivindicación de «los derechos fundamentales de la sociedad», ya mencionados con anterioridad y sobre los que previene tan certeramente Carrió. Sobre los derechos humanos de la tercera generación y sus rasgos diferenciales ver, A. E. Pérez Luño, «las generaciones de los derechos humanos», en R.C.E.C., n. ${ }^{\circ} 10$, septiembre-diciembre 1991, págs. 203 y ss. y concretamente sobre la libertad informática y el derecho a la autodeterminación informativa, cfr. del mismo autor, «Intimidad y protección de datos personales: del habeas corpus al habeas data» en A.A.V.V., Estudios sobre el derecho a la intimidad, op . cit. Con respecto al problema de la titularidad colectiva en materia de derechos fundamentales puede verse entre otros, A. D. Carrió, «Derecho constitucional a la privacidad...» ya cit. o la parte dedicada a Los sujetos de los derechos humanos del colectivo Los derechos humanos, ed. J. Ballesteros, Tecnos, Madrid, 1992, especialmente el capítulo de E. Bea, «Los derechos de las minorías nacionales: su protección internacional, con especial referencia al marco europeo», págs. 163 y ss. Finalmente puede resultar interesante confrontar J. De Lucas, «El racismo como coartada», A.D. y $L$. n. $^{\circ} 2$, Madrid, 1992, donde tras señalar lo ineludible de enfrentarse al problema de la titularidad de los derechos de las minorías apuntará que «...lo importante es reconocer y garantizar los derechos a quienes son sus titulares: los individuos, pertenezcan o no a las minorías del tipo que fuere. Otra cosa es desconocer que esa pertenencia modifica no sólo las condiciones reales de ejercicio de los derechos, sino incluso la posibilidad misma de su atribución, de su reconocimiento». Para terminar concluyendo en que «...es cierto que cuando hablamos de derechos de las minorías, tratamos de proteger sobre todo derechos individuales, pero también algo más que ellos». 